\title{
Article
}

\section{GmFULc Is Induced by Short Days in Soybean and May Accelerate Flowering in Transgenic Arabidopsis thaliana}

\author{
Jingzhe Sun, Mengyuan Wang, Chuanlin Zhao, Tianmeng Liu, Zhengya Liu, Yuhuan Fan, Yongguo Xue, Wenbin Li, \\ Xiaoming Zhang * and Lin Zhao *
}

check for

updates

Citation: Sun, J.; Wang, M.; Zhao, C.; Liu, T.; Liu, Z.; Fan, Y.; Xue, Y.; Li, W.; Zhang, X.; Zhao, L. GmFULc Is Induced by Short Days in Soybean and May Accelerate Flowering in Transgenic Arabidopsis thaliana. Int. J. Mol. Sci. 2021, 22, 10333. https:// doi.org/10.3390/ijms221910333

Academic Editor: Bin Liu

Received: 27 July 2021

Accepted: 22 September 2021

Published: 25 September 2021

Publisher's Note: MDPI stays neutral with regard to jurisdictional claims in published maps and institutional affiliations.

Copyright: (c) 2021 by the authors. Licensee MDPI, Basel, Switzerland. This article is an open access article distributed under the terms and conditions of the Creative Commons Attribution (CC BY) license (https:// creativecommons.org/licenses/by/ $4.0 /)$.
Key Laboratory of Soybean Biology of Ministry of Education China, Northeast Agricultural University, Harbin 150030, China; jingzhesun0306@126.com (J.S.); wmy8977@126.com (M.W.); z1390421338@126.com (C.Z.); 1tm0729@126.com (T.L.); xiaochengai2021@126.com (Z.L.); fyh1404207035@126.com (Y.F.); xyg81@126.com (Y.X.); wenbinli@neau.edu.cn (W.L.)

* Correspondence: zhangxiaoming@neau.edu.cn (X.Z.); linzhao@neau.edu.cn (L.Z.)

\begin{abstract}
Flowering is an important developmental process from vegetative to reproductive growth in plant; thus, it is necessary to analyze the genes involved in the regulation of flowering time. The MADS-box transcription factor family exists widely in plants and plays an important role in the regulation of flowering time. However, the molecular mechanism of GmFULc involved in the regulation of plant flowering is not very clear. In this study, GmFULc protein had a typical MADS domain and it was a member of MADS-box transcription factor family. The expression analysis revealed that GmFULc was induced by short days (SD) and regulated by the circadian clock. Compared to wild type (WT), overexpression of GmFULc in transgenic Arabidopsis caused significantly earlier flowering time, while ful mutants flowered later, and overexpression of GmFULc rescued the late-flowering phenotype of $f u l$ mutants. ChIP-seq of GmFULc binding sites identified potential direct targets, including TOPLESS (TPL), and it inhibited the transcriptional activity of TPL. In addition, the transcription levels of FLOWERING LOCUS T (FT), SUPPRESSOR OF OVEREXPRESSION OF CONSTANS1 (SOC1) and LEAFY (LFY) in the downstream of TPL were increased in GmFULcoverexpression Arabidopsis, suggesting that the early flowering phenotype was associated with upregulation of these genes. Our results suggested that GmFULc inhibited the transcriptional activity of TPL and induced expression of FT, SOC1 and LFY to promote flowering.
\end{abstract}

Keywords: soybean; GmFULc; photoperiod; flowering time; TPL

\section{Introduction}

Soybean [Glycine max (L.) Merrill] is a typically SD plant, as its vegetative and reproductive growth are closely related to the photoperiod [1]. The soybean switches from vegetative growth to reproductive growth only after the length of daylight is shortened to a critical limit. Due to the photoperiod sensitivity characteristic of soybean, when it is planted at higher latitudes, where it is exposed to long-day (LD) conditions in the growing season, they often show late flowering, the growth period is prolonged, and they might not even flower or mature normally; conversely, when it is planted at lower latitudes, where it is exposed to shortened lengths of daylight in the growing season, it generally shows early flowering, shortening of the growing period, reduction of yield and even failure of normal growth. The flowering and maturity of soybean are seriously affected by the length of the growing season in the planting region, so that the geographical adaptative region of soybean varieties are generally narrow, and the photoperiod response characteristic is an important factor affecting the regional adaptability of soybean varieties [2-4]. Therefore, it is necessary to clarify the molecular mechanism of some genes involved in the photoperiod pathway, in order to provide a basis for the cultivation of soybean varieties that have a relatively wide regional adaptability. 
Many members of the MADS-box transcription factor family, which play key roles in plant development processes, including flowering induction, flowering time, formation of floral meristems and organs, fruit formation and seed pigmentation, such as FUL, APETALA1 (AP1), CAULIFLOWER (CAL), SEPALLATA (SEP) 1/2/3 and AGAMOUS (AG), are involved in the formation of flowers, and MADS-box proteins can form heterodimers with other proteins to regulate flowering [5-7]. The floral organ identity gene FUL in Arabidopsis contains a MADS-box domain, also known as AGL8(AGAMOUS-LIKE8), which belongs to the $A P 1 / F U L$-like gene subfamily with $A P 1$ and $C A L[8,9]$. The FUL gene has broader functions compared to AP1 and CAL: it promotes the formation of inflorescence, dividing tissue in early flower development, but also in the late flower development pericardial and young horn fruit, and also regulates leaf development [10]. In the photoperioddependent flowering pathway, CONSTANS (CO) integrates various photoperiod regulatory genes, and the activated FT is expressed in the leaf vascular bundles. FT is then transported to the apical meristems, triggering the expression of FUL and SOC1 in the apical meristems. FUL is involved in the regulation of the transformation from flower bud meristems to inflorescence meristems, and then FUL and SOC1 are expressed in the developing inflorescence meristems layer to induce the transformation to floral meristems, thus controlling the flowering time [11]. Expression of florigen gene FT is induced by LD in the leaves, and then the FT is transported from leaves to apical meristems and binds to the FD protein. The FT/FD protein complex in the apical meristems promote the expression of the characteristic gene $F U L / S O C 1$ of the floral meristems to induce flowering [12,13]. FUL induces flowering by antagonizing the effect of FLC flowering time inhibitor, SVP interacts with FLC protein to inhibit flowering and FUL interacts with SVP protein to antagonize the inhibitory effect of FLC on flowering, after which FUL interacts with SOC1 protein to form FUL and SOC1 dimers that bind to the $L F Y$ promoter, thereby promoting $L F Y$ expression and inducing flowering $[14,15]$. The conserved sequence of MADS-box protein and DNA binding is generally CC (A/T) ${ }_{6} \mathrm{GG}$, called CArG-box [16].

Similar to AtFUL, rice FUL-type factors are involved in flower initiation as characteristic genes of floral meristems. PAP2 is a member of the SEPALLATA subfamily, and it interacts with MADS14 and MADS15 to promote the transition of vegetative meristems to inflorescence meristems. Different from Arabidopsis, rice FUL-type factors also act in the leaves upstream of $H d 3 a / R F T 1$ and participate in the regulation of flowering time [17]. During tomato ripening, FUL1 and FUL2 act on the upstream of the ethylene signal pathway to promote fruit ripening [18-20]. In cucumber, $C s F U L 1^{A}$ is a gain of function allele in long-fruited cucumber and its expression level manipulating fruit length [21]. Soybean MADS-box gene, AGAMOUS-LIKE1(GmAGL1) played a role in floral organ formation and dehiscence, and promotes flowering in the photoperiod pathway [22,23]. GmFLC-like (FLOWERING LOCUS C) is the member of FLC clade of the MADS-box transcription factor family and participates in late flowering triggered by long-term low temperature by inhibiting the expression of $F T$ [24]. Recent studies have found that in the photoperiod pathway, GmGBP1 interacting with GmGAMYB might regulate flowering time by up-regulating the transcriptional level of GmFULc $[25,26]$. TPL participates in various molecular pathways, such as the circadian clock, flowering time regulation, auxin, jasmonic acid and ethylene hormone signaling in Arabidopsis [27-29]. The tpl mutant decreased photoperiod sensitivity and showed early flowering by reducing the expression level of $F T$ [30]. The aim of our study is to clarify the molecular mechanism of GmFULc, promoting flowering through the soybean photoperiod effect, further providing a new way for improving the growth period of soybean.

In this study, GmFULc was identified as a member of the MADS-box transcription factor family. Transgenic Arabidopsis with GmFULc overexpression has the early flowering phenotype. ChIP-seq predicted the possible target gene TPL and preliminarily confirmed that GmFULc promotes flowering by inhibiting the activity of TPL. In addition, GmFULc-ox increased the expression of flowering-related genes $F T, S O C 1$ and $L F Y$. 


\section{Results}

\subsection{Sequence Analysis of the GmFULc}

GmFULc (Glyma.05G018800.2) might play a crucial role in promoting flowering in soybean [25]. The gene was cloned from soybean variety "DongNong 42" according to the referencing Phytozome database (https: / / phytozome.jgi.doe.gov/pz/portal.html, accessed on 1 April 2021). The cDNA sequence of GmFULc is $1149 \mathrm{bp}$, containing the ORF of $720 \mathrm{bp}$, encoding 239 amino acids, and the predicted molecular weight was $27.55 \mathrm{kDa}$. GmFULc has a MADS domain at the N-terminal, followed by a K-domain (keratin-like), which is predicted at amino acid residues 1-79 and 88-174, respectively (Figure 1A). Phylogenetic tree containing four soybean proteins and eight FUL proteins from other species was constructed. GmFULc/d were classified into the one branch with Vigna unguiculata (XP_027922086.1), Cajanus cajan (XP_020227938.1), Abrus precatorius (XP_027333786.1), Cicer arietinum (XP_004508656.1), Pisum sativum (AFI08227.1), Lupinus albus (KAE9601902.1) and Medicago secundiflora (AFU81360.1) (Figure 1B). These indicate that the protein encoded by GmFULc/d may be a relatively conserved protein in leguminous crops. AtFUL is closely related to $\mathrm{GmFULa} / \mathrm{b}$, indicating that GmFULa/b may have similar biological functions to AtFUL (Figure 1B). The evolution distance between GmFULc/d and GmFULa/b was relatively far, indicating that there may be some differences in the function of FUL proteins in soybean. We compared the amino acid sequence of GmFULc with the FUL homologous proteins of other species. The sequence of MADS domain of GmFULc is highly conserved among some species, while the conservation of K-domain was much weaker (Figure 1C).

\subsection{Photoperiod and the Circadian Clock Regulate the Expression of GmFULc}

Soybean trifoliate leaves grown for 20 days were collected every $3 \mathrm{~h}$ and the daily expression pattern of GmFULc under SDs and LDs was analyzed by qRT-PCR. GmFULc showed photoperiod specific expression patterns in SDs and LDs. The expression levels of GmFULc in SDs were higher than LDs (Figure 2A). The expression pattern of GmFULc was analyzed after SDs and LDs transfer under constant light (LL) and darkness (DD) conditions. Under the condition of SDs-DD and SDs-LL, the level of GmFULc mRNA maintained a strong rhythm and reached the peak at ZT $12 \mathrm{~h}$ (Figure 2B,C). Therefore, GmFULc was regulated by the circadian rhythm and induced by SDs in soybean leaves.

\subsection{The tissue-specific Expression Patterns of GmFULc in Soybean}

In order to study the tissue-specific expression patterns of GmFULc during growth and development of soybean, different tissues of soybean (root, stem, leaf, flower, pod and seed), treated with SDs and LDs, were collected $12 \mathrm{~h}$ after dawn. The expression level of GmFULc was the highest in the roots and leaves under SDs and LDs, respectively. In roots, stems and leaves, the expression level of GmFULc was higher in SDs than that in LDs. There was no significant difference of GmFULc mRNA abundance in seeds between SDs and LDs (Figure 2D).

\subsection{Overexpression of GmFULc May Accelerate Flowering in Transgenic Arabidopsis}

GmFULc was transformed into Arabidopsis under the control of a CaMV 35S promoter and GmFULc-ox transgenic Arabidopsis were obtained. The flowering phenotypes of WT, GmFULc-ox, GmFULc-ox/ful and ful mutants were observed in SDs and LDs. The flowering time of GmFULc-ox transgenic Arabidopsis were advanced by 6 days in LDs, while flowering time of $f u l$ mutants was delayed by 2 days. Complementary experiments on ful mutants were carried out. The expression of 35S:GmFULc rescued the late-flowering phenotype of ful mutants. The number of rosette leaves of GmFULc-ox transgenic Arabidopsis and ful mutants were less and more than that of WT during bolting, respectively (Figure 3A,B). The flowering time of GmFULc-ox was earlier than that of ful mutants by 5 days in SDs (Figure $3 \mathrm{~A}, \mathrm{C}$ ). The results showed that overexpression of GmFULc promote flowering in transgenic Arabidopsis. 

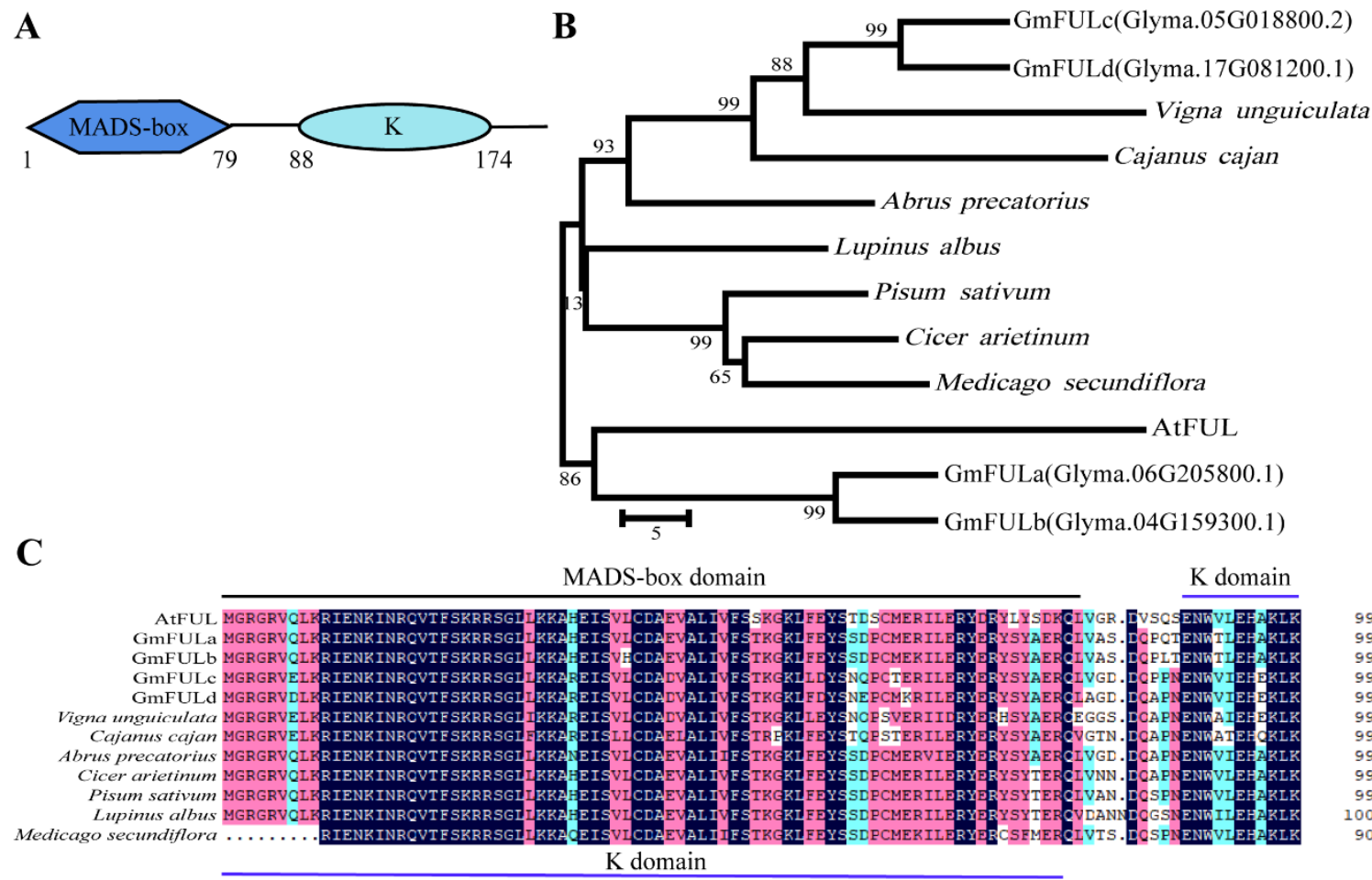

domain

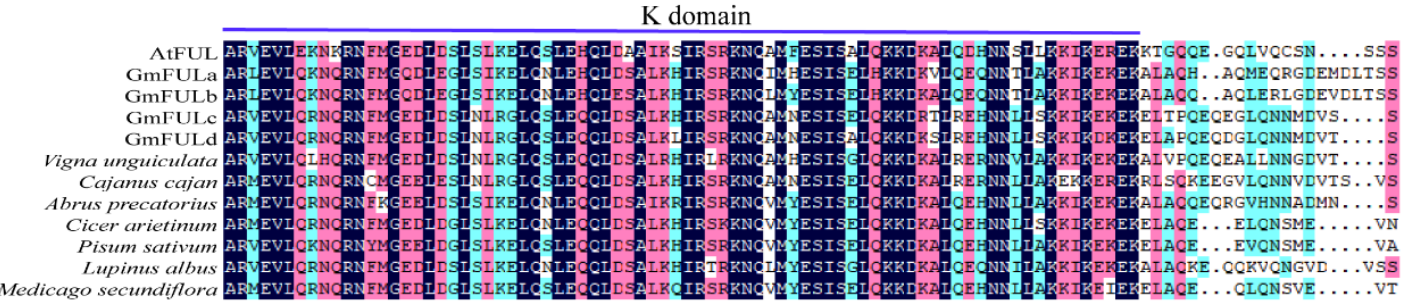

194
197
197
195
195
195
197
195
191
191
196
182

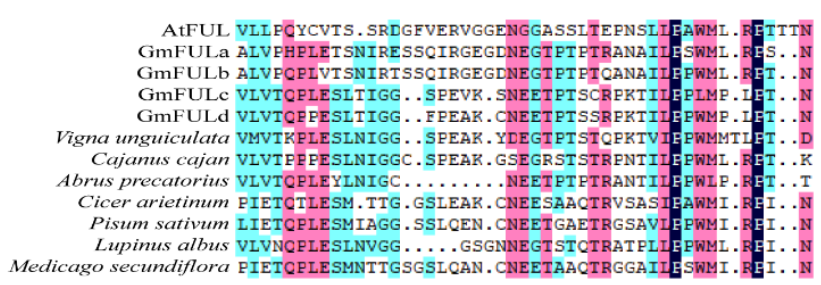

Figure 1. Sequence and phylogenetic tree analysis and subcellular localization of GmFULc. (A) Predicted domains of GmFULc. (B) Phylogenetic relationships of GmFULc and some FUL proteins from other species. Accession numbers are listed in Supplementary Table S1. Phylogenetic tree containing four soybean proteins with the complete MADS-box domain and eight FUL proteins from Arabidopsis thaliana, Vigna unguiculata, Cajanus cajan, Abrus precatorius, Cicer arietinum, Pisum sativum, Lupinus albus and Medicago secundiflora. Phylogenetic tree was constructed using the neighbor joining method with 1000 bootstrap replicates by MEGA 6.0. (C) Sequence alignment of GmFULc and other FUL proteins from other species. The MADS and K-domain were indicated by the line on the top. The black line and the blue line mark the MADS-box domain (1-79 aa) and the K-domain (88-174 aa), respectively. Light blue, homology $\geq 50 \%$; pink, homology $\geq 75 \%$; blue, homology $100 \%$. 
$\mathbf{A}$

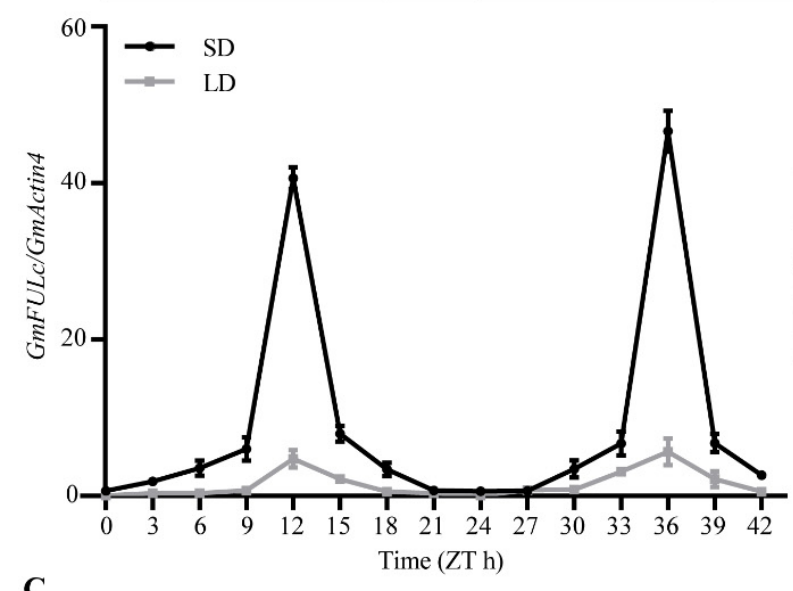

C

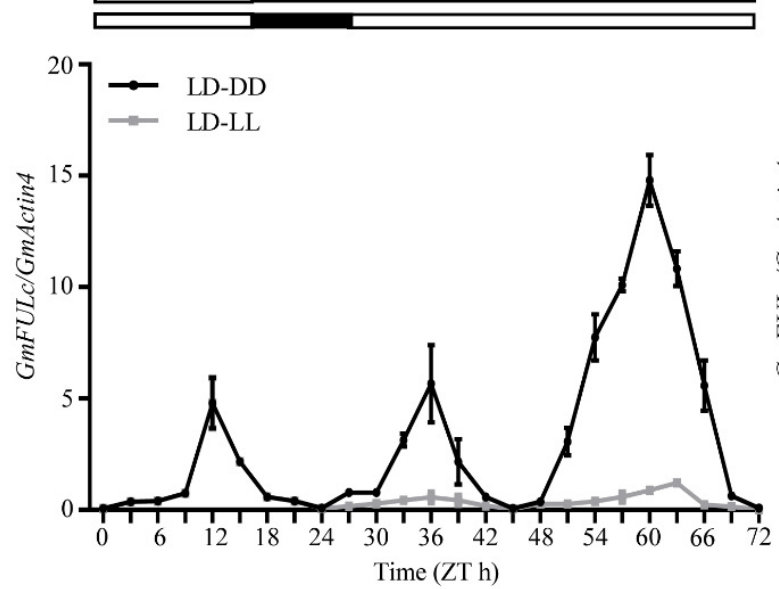

B

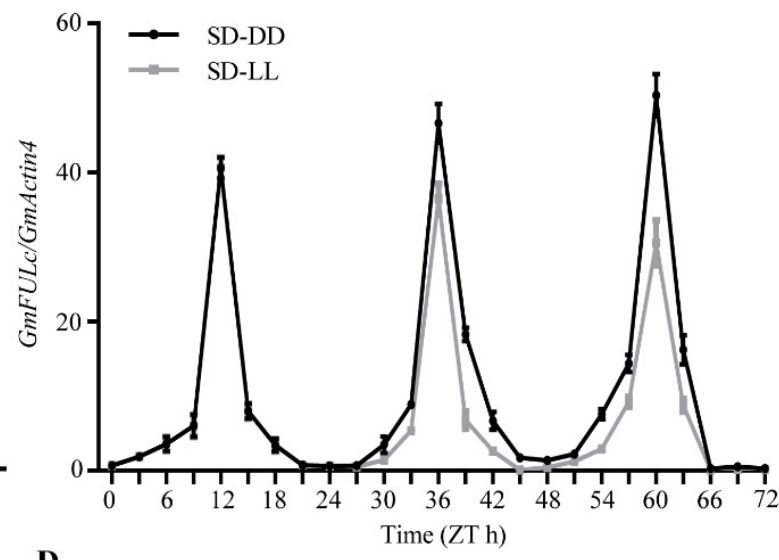

D

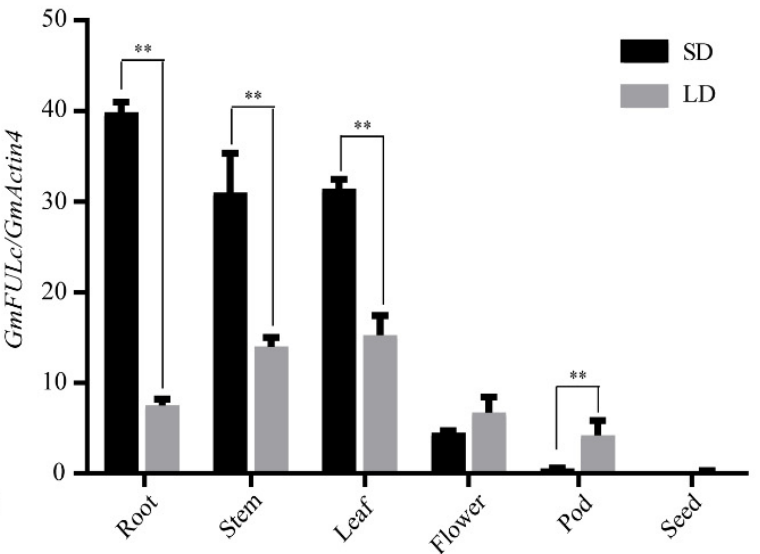

Figure 2. GmFULc expression patterns analysis. A photoperiod-sensitive soybean variety, "Dongnong 42 ", was grown in LDs (16 h light/ $8 \mathrm{~h}$ dark) for 10 days and then transferred to SDs ( $8 \mathrm{~h}$ dark $/ 16 \mathrm{~h}$ light) or LDs for sampling at 3-h interval. (A) The expression levels of GmFULc in SDs and LDs. (B) Expression patterns of GmFULc transcripts under LL and DD conditions from SDs. (C) Expression patterns of GmFULc in LL and DD conditions from LDs. White and black bars at the top represent the light and dark phases, respectively. (D) Tissue-specific expression of GmFULc at ZT $12 \mathrm{~h}$ in SDs and LDs. Data are means \pm standard errors of the mean (SEM) of three independent experiments. Significant differences between the expression level of GmFULc under SDs and LDs are indicated by asterisks. Student's $t$-test, ${ }^{* *} p<0.01$. 
A

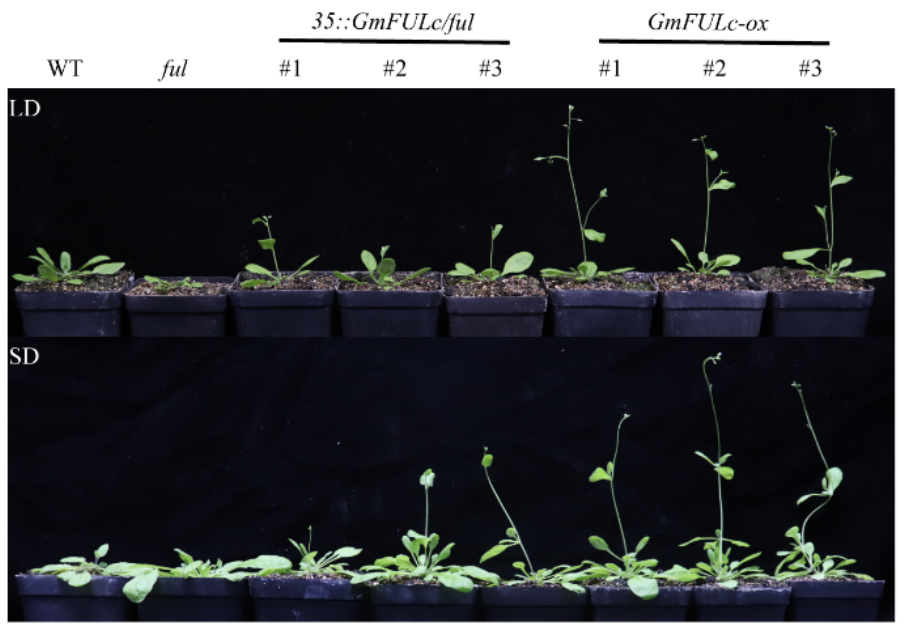

C

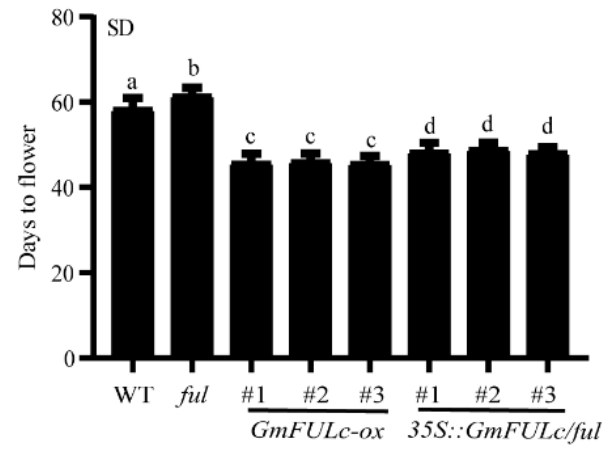

B
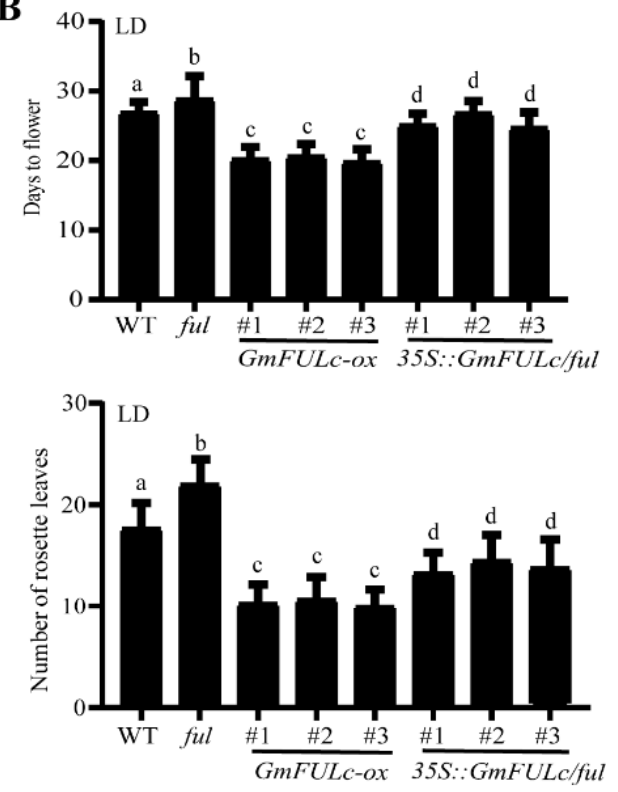

Figure 3. Phenotypes of transgenic Arabidopsis in SDs and LDs. (A) Flowering phenotype of GmFULc-ox, ful mutant, 35S:GmFULc/ful restoration and WT plants in SDs and LDs. Photographed after the plants were grown in SDs and LDs for 55 days and 28 days, respectively. (B) Days to flower and number of rosette leaves of GmFULc-ox, ful mutant, 35S:GmFULc/ful and WT in LDs. (C) Days to flowering and number of rosette leaves of GmFULc-ox, ful mutant, 35S:GmFULc/ful and WT in SDs. Data are shown as means \pm SEM. For each experiment, three technical replicates were conducted. One-way ANOVA was used to generate the $p$ values. The same letter denotes nonsignificant differences across the two panels $(p>0.05)$.

\subsection{Chromatin Immunoprecipitation Sequencing Assays of GmFULc-Target Genes}

The target genes of GmFULc were identified by ChIP-seq technique to further clarify the possible mechanism of GmFULc promoting flowering. Among the $234 \mathrm{GmFULc}$ binding sites detected, $182(77.77 \%)$ sites were located at gene regions. Among the 182 sites in genic regions, $21.37 \%, 20.94 \%, 11.11 \%$ and $13.25 \%$ were located in defined promoter regions, exon, intron and TTS, respectively (Figure 4A). TPL (AT1G15750) might be a candidate target gene for GmFULc. In Arabidopsis, TPL plays a role in inhibiting flower transition in the upstream of floral integrator $F T$ [30]. 
A

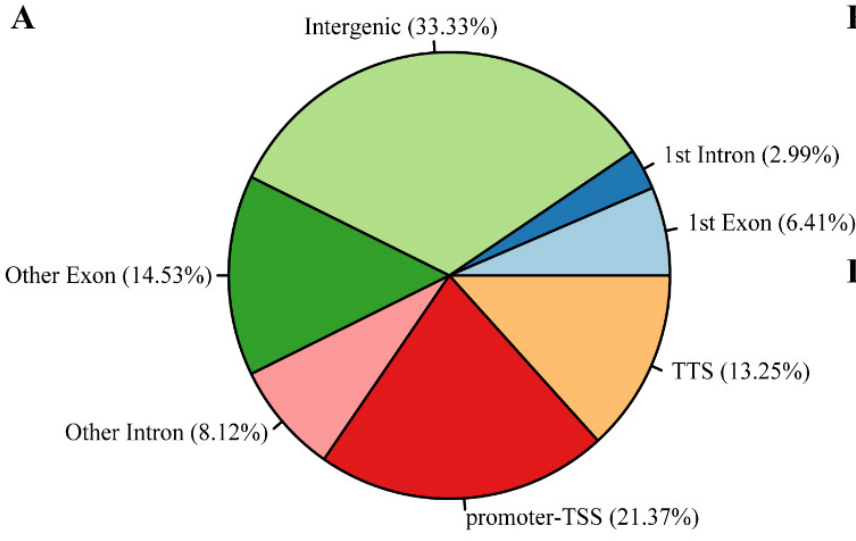

C

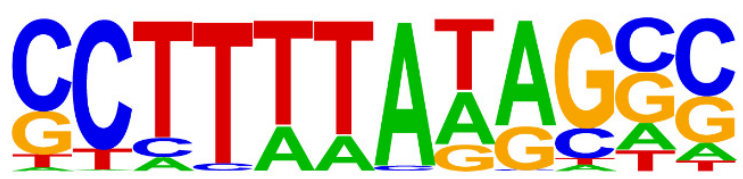

$\mathbf{F}$
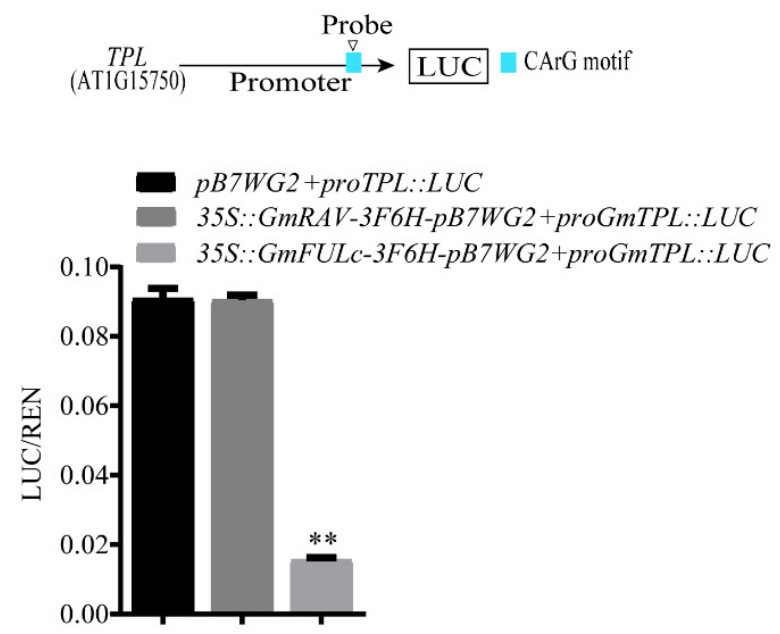

B

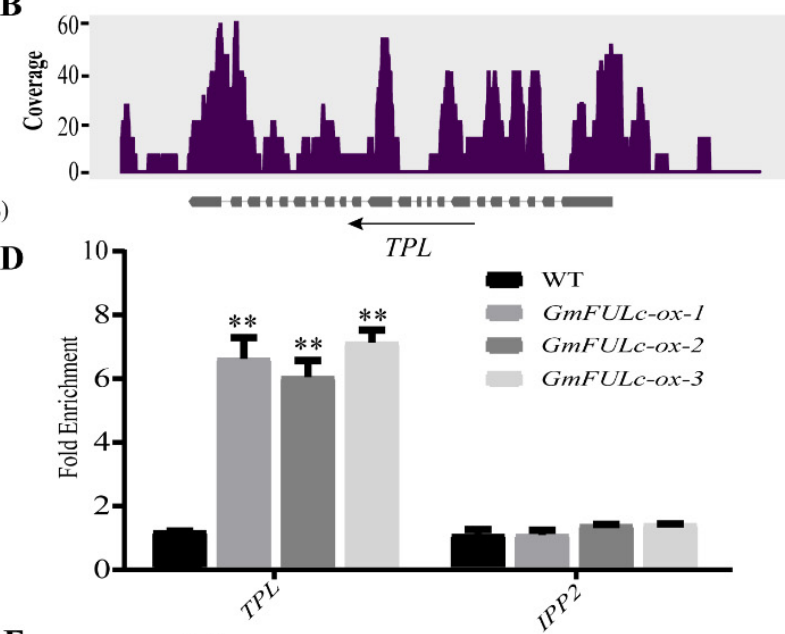

$\mathbf{E}$

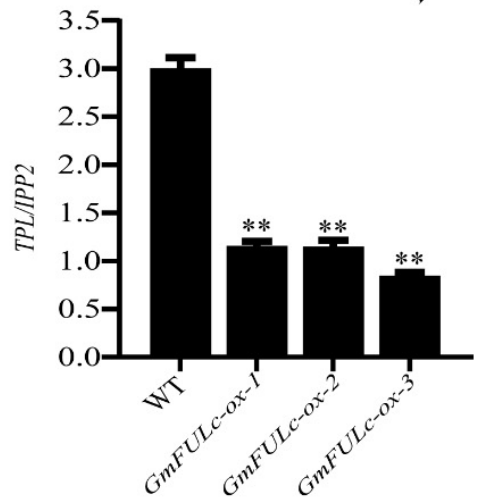

G
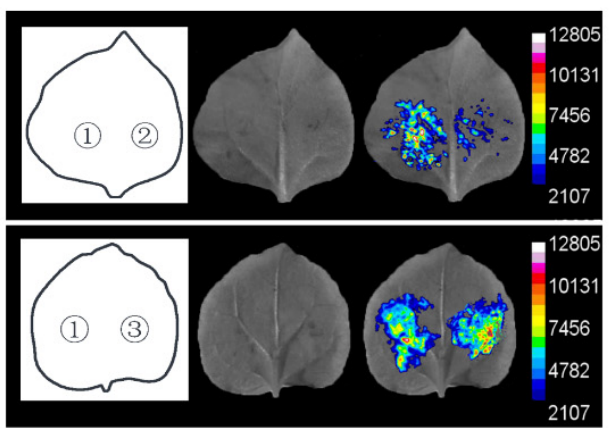

Figure 4. Validation and expression analyses of the selected GmFULc target genes. (A) The binding sites are distributed relative to the position of the target genes. (B) Peak diagram showing the designated gene loci in the ChIP-seq raw reading in the integrated genome observer. The arrow indicates the direction of the transcription. (C) Motif analysis of GmFULcbinding sequences using Hypergeometric Optimization of Motif EnRichment (HOMER) software. (D) ChIP-qPCR from GmFULc-ox transgenic Arabidopsis and WT plants. (E) The mRNA abundance of TPL in the 14-day-old plants. (F) Upper panel: the physical location of the base sequence fragments. The effect of GmFULc on the TPL promoter activity. Relative LUC activity of cotransfected reporter and effector in N. benthamiana leaves. Data are shown as means \pm SEM of three independent experiments. Student's $t$-test, ${ }^{* *} p<0.01$. (G) The LUC activities of TPL. 1: $p B 7 W G 2+$ proTPL:LUC were used as the blank control; 2: 35S:GmFULc-3F6H-pB7WG2 + proTPL:LUC; 3: 35S:GmRAV-3F6H-pB7WG2 + proTPL:LUC was used as the negative control; D-luciferin was used as the substrate of LUC.

The GmFULc binding site of the TPL genome is located at the promoter (Figure 4B). According to the common sequences of GmFULc binding sites detected, the possible GmFULc binding motifs were predicted by HOMER software [31]. According to the predicted results, we determined that GmFULc binds to the target gene TPL motif CArGbox $\left(p\right.$-value $\left.=1 \times 10^{-4}\right)$ (Figure $\left.4 \mathrm{C}\right)$. AtFUL regulated SAUR10 by binding conserved CArG-box of its promoter [32]. The promoter of TPL contained the CArG-box, which was 
similar to the CArG-box combined with the AtFUL and SAUR10 promoter. In the ChIPqPCR experiment, the fragments containing GmFULc binding sites in the TPL promoter region were highly enriched in ChIP with Anti-FLAG, indicating that GmFULc binds to the TPL promoter (Figure 4D).

\subsection{GmFULc Inhibits the Transcriptional Levels of TPL}

ChIP-qPCR found that the TPL promoter was bound by GmFULc, and qRT-PCR found that the mRNA abundance of TPL was decreased in GmFULc-ox Arabidopsis. Reporter proTPL:LUC was constituted of a TPL promoter driving the LUC reporter gene. The LUC activity of co-infiltrating $p B 7 W G 2$ and proTPL:LUC was lower than co-infiltrating 35S:GmFULc-3F6H-pB7WG2 and proTPL:LUC into N. benthamiana leaves, indicating that GmFULc inhibit the expression level of TPL. The LUC activity with the floral repressor GmRAV [33] and proTPL:LUC co-transformed the leaves of N. benthamiana, which showed no difference compared with the control (Figure $4 \mathrm{~F}, \mathrm{G}$ ). In summary, GmFULc significantly inhibited the transcriptional levels of TPL by directly binding to its promoter.

\subsection{GmFULc Affects the Transcriptional Levels of Flowering Time Related Genes}

Overexpression of GmFULc led to early flowering in Arabidopsis. In order to further investigated the regulation mechanism of GmFULc on flowering time, the transcriptional levels about flowering-related genes (including FT, LFY, SOC1 and CO) in 14-day-old plants. The expression levels of $F T$, floral meristems recognition $L F Y$ and floral integration SOC1 in transgenic plants with GmFULc-ox were significantly higher than that in WT plants, but $L F Y$ and SOC1 significantly decreased in ful mutants. In 35S:GmFUL/ful, the down-regulated trend of $S O C 1$ and $L F Y$ were rescued (Figure 5A-C). The transcriptional levels of $C O$ were not significantly different from that of WT (Figure 5D). FT, LFY and SOC1 play roles in the downstream of TPL [30]. In summary, GmFULc inhibited the expression of TPL, and induced the transcriptional levels of $F T, L F Y$ and $S O C 1$ to promote flowering in Arabidopsis.

A

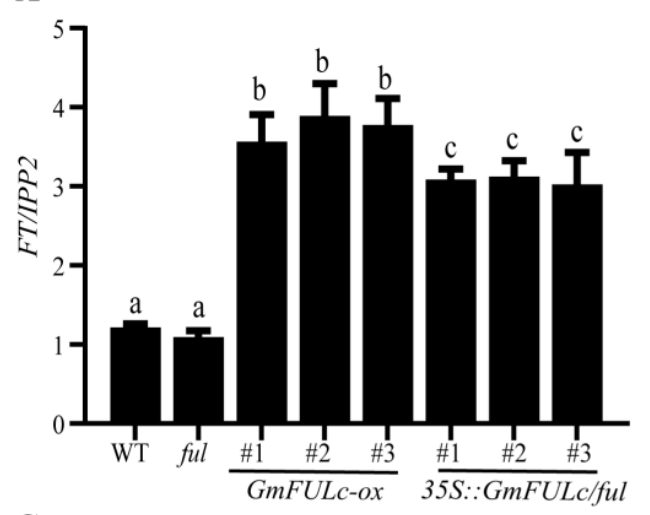

C

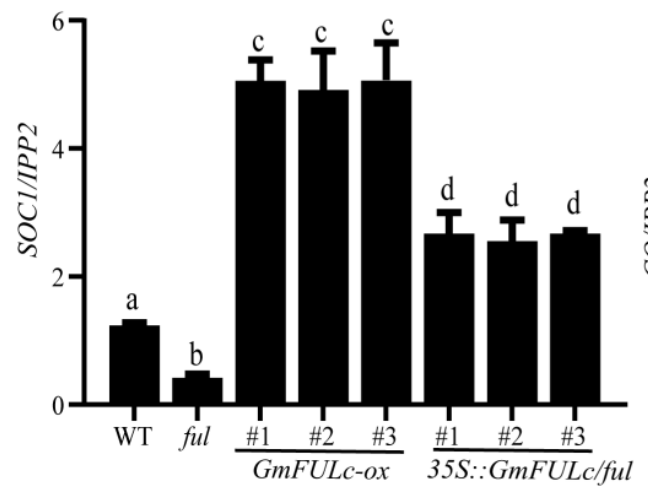

B

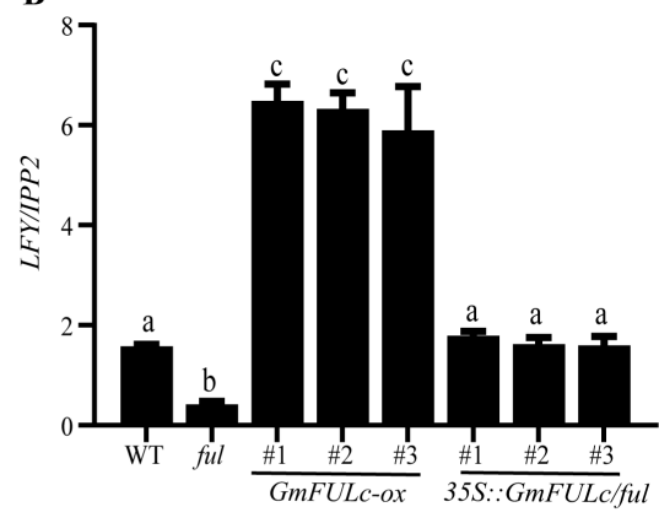

D

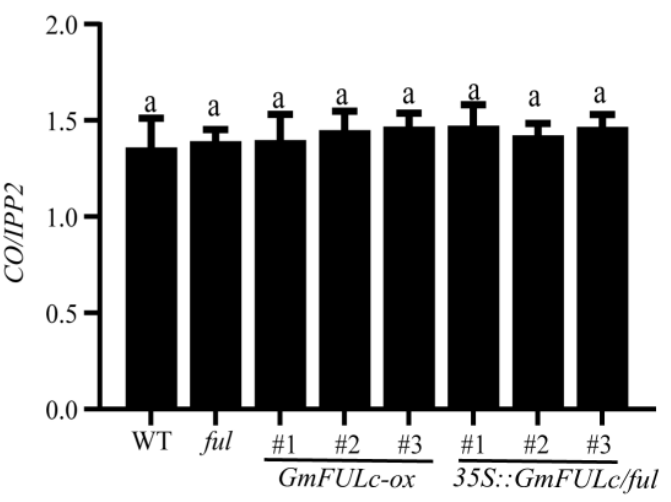

Figure 5. The transcriptional levels of $F T$, LFY, SOC1 and CO in GmFULc-ox, ful mutants, 35S:GmFULc/ful 
and WT plants. (A-D) GmFULc-ox, ful mutants, 35S:GmFULc/ful and WT plants were planted in LDs, and sampled to determine the transcriptional levels of FT, LFY, SOC1 and CO at ZT $12 \mathrm{~h}$. Data are shown as means \pm SEM of three independent experiments. For each experiment, three technical replicates were conducted. One-way ANOVA was used to generate the $p$ values. The same letter denotes nonsignificant differences across the two panels $(p>0.05)$.

\section{Discussion}

Members of the MADS-box transcription factor family contain a highly conserved domain called the MADS-box domain, which are widely found in plants [34]. Some members of the MADS-box family have been reported in Arabidopsis, rice, tomato and cucumber [15]. However, the function of GmFULc has not been reported in soybean. In this study, GmFULc was isolated and identified from soybean. GmFULc was identified as a member of the MADS-box family. In addition, the MADS-box domain between the GmFULc and FUL proteins from some species shared high conservation (Figure 2B,C). The AP1/FUL subfamily of MADS-box genes may originate from repeated events before the differentiation of existing angiosperms [35].

The transcript levels of GmFULc were relatively more expressed in stems, but at lower level in seeds of soybean (Figure 2D). FUL is negatively regulated by AP1 in the early stages of Arabidopsis development. FUL is almost not expressed in the early vegetative organs; until Arabidopsis transits to reproductive growth, FUL is strongly expressed in the inflorescence meristems, and its expression patterns are different from soybean [8]. Although GmFULc and AtFUL have amino acid homology, there may be some evident differences in biological function that need to be further clarified. Analysis of GmFULc expression pattern suggested that GmFULc was regulated by the circadian rhythm and induced by SDs in soybean leaves.

The homologue gene of GmFULc, GmFULa expression level was affected by photoperiod conditions, but not affected by diurnal rhythm [36].

Overexpression of GmFULc in Arabidopsis showed early flowering and the ful mutants showed late flowering in SDs and LDs. Compared with the ful mutant, the phenotype of the 35S:GmFULc/ful complementary line were rescued (Figure 3A). Therefore, the transcriptional level of GmFULc was regulated by day length and might participate in the regulation of flowering at Arabidopsis. The loss of AtFUL function led to delayed flowering in SDs and LDs, while the overexpression of AtFUL caused an early flowering phenotype [10,11]. Furthermore, the overexpression of GmFULc in Arabidopsis led to a significantly early flowering phenotype compared with the wild type (Figure 3A). The transcriptional levels of LFY, SOC1 and FT increased significantly in transgenic Arabidopsis (Figure 5).

In the photoperiod pathway, FUL is target of FT and FD function during flowering. The high expression level of FT further increases the expression of FUL and leads to morphological changes in leaves. The accumulation of FUL in meristems is related to the transition of flowering [37]. Different from Arabidopsis, rice is an SD plant, and thus, SEPALLATA MADS-box gene PAP2 and the AP1/FUL-like genes (MADS14, MADS15 and $M A D S 18)$ were located upstream and induced expression of $H d 3 a$ and RFT1 in rice leaves. $A P 1 / F U L$-like genes play different roles to promote reproductive transition. The FT is transported from leaves to SAM, while PAP2, MADS14, MADS15 and MADS18 were induced in SAM. These regulations might help to accelerate the changing meristems phase by magnifying the florigen signal [17]. The distinct ways that AtFUL and GmFULc function could be due to differences between species. The working mode of GmFULc is similar to that of the AP1/FUL-like genes in rice. These may be the reason that transcript levels of GmFULc were higher than that of AtFUL in the leaves, but this speculation has not been confirmed. The mechanism of GmFULc regulating soybean flowering might be different from that of AtFUL, which needs to be clarified. This suggests that both GmFULc and AtFUL promote the flowering of Arabidopsis, and they may be functionally distinct in some aspects [15]. 
The expression of GmFULa and GmFULb (soybean FUL homolog genes) were inhibited by GmFT1a and delayed flowering in soybean [38]. It has been suggested that different genes in the same family may perform different functions in soybean, and this needs to be clarified. In order to confirm the potential targets of GmFULc, GmFULc-ox transgenic Arabidopsis were used to predict the target genes of GmFULc by ChIP-seq. By screening the genes in which GmFULc binds to the promoter region, a flowering-related gene, TPL, was identified. In Arabidopsis, TPL was a transcription mediator in various molecular pathways, such as flowering time regulation, leaf development, anthocyanin accumulation, auxin and jasmonate signaling transduction pathway [27-29,39-42]. The formation of the CDF-TPL complex reduces the expression of FT, LFY and SOC1 play roles in the downstream of TPL [30]. A CArG-box CTTTTAAGG is located at the TPL promoter region, similar to the reported AtFUL binding motif CCAAATATGG in the SAUR10 promoter region [32]. GmFULc reduced the transcriptional activity of TPL and GmFULc-ox transgenic Arabidopsis showed the expression of TPL decreased significantly when the expression of LFY, SOC1 and FT increased. GmFULc can promote flowering by repressing TPL transcriptional activity in Arabidopsis.

\section{Materials and Methods}

\subsection{Plant Materials, Growth Conditions and Records of Data}

For the analysis of GmFULc, we used seeds from a photoperiod-sensitive soybean variety, "DongNong 42". Seeds were planted in growth chambers at $28^{\circ} \mathrm{C}$ in LDs $(16 \mathrm{~h}$ light $/ 8 \mathrm{~h}$ dark), and when expanding the trifoliate leaves, partial plants were transferred to SDs (8 h light/16 h dark) under the same environmental conditions with LDs. The seedlings were sampled at every 3-h interval under SDs and LDs (transferred in 15 days), continuous light (LL) and dark (DD). Samples were collected under SDs and LDs from different tissues, including root, stem, leaf, flower, pod and seed. Arabidopsis thaliana (Columbia-0) was used for genetic transformation. Seeds from the ABRC were obtained from the ful mutant (SALK_033647). GmFULc-ox, ful mutant, 35S:GmFULc/ful and WT seeds were planted on $1 / 2 \mathrm{MS}$ agar medium. Seeds were vernalized for 3 days and transferred to the growth chambers $\left(22^{\circ} \mathrm{C}\right)$, and 12-day-old seedlings were transferred to 1:1 of vermiculite and turfy-soil for flowering phenotype analysis at SDs and LDs. GmFULc-ox, 35S:GmFULc/ful and WT were cultured under the LDs of 1/2MS agar medium, and qRT-PCR analyses were carried out for flowering-related genes. Flowering time was measured by the number of days from germination to bolting. Means \pm SEM deviation was used in the statistical analysis of the data. At least 20 plants were analyzed for each cultivar and each time, and the experiments were repeated three times.

\subsection{Plasmid Construction and Generation of Transgenic Arabidopsis Plants}

The $p E N T R Y-3 F 6 H$ included the $3 \times$ FLAG and $6 \times$ His [43]. The PCR products were cloned into $p E N T R Y-3 F 6 H$ linearized by SmaI using In Fusion cloning to construct recombinant 35S:GmFULc-3F6H-pENTRY and recombinant vector 35S:GmFULc-3F6H - pB7WG2 was transformed into WT and ful mutants by the floral dip method [44] using the Agrobacterium GV3101. Seeds were selected with $6 \mathrm{mg} / \mathrm{L}$ phosphinothricin on 1/2 MS agar medium. Three homozygous lines of $\mathrm{T}_{3}$ transgenic seeds were chosen for further research.

\subsection{ChIP-Seq and ChIP-qPCR}

GmFULc-ox-1 transgenic Arabidopsis plants were mixed and sampled, and then $0.6 \mathrm{~g}$ seedlings were frozen. ChIP experiments were performed as previously described [45]. IP were performed using Anti-FLAG antibody (Monoclonal ANTI-FLAG®M2 antibody, F1804, Sigma-Aldrich, Saint Louis, MO, USA) and Anti-IgG antibody (Normal Rabbit IgG antibody, 2729, Cell Signaling Technology, Danvers, MA, USA). The DNA was sent to a sequencing company for sequencing. 


\subsection{Transient Assay of TPL Promoters Affected by GmFULc in N. Benthamiana}

To generate TPL promoter-driven LUC constructs proTPL:LUC, the promoter of TPL was amplified from genomic DNA of Arabidopsis using proTPL:LUC-F and proTPL:LUC-R primers (Table S2). The PCR product was purified and cloned into binary vector $p$ GreenII0800-LUC, linearized by SmaI using In-Fusion cloning system (Takara, Beijing, China). The constructs 35S:GmFULc-3F6H-pB7WG2 and proTPL:LUC were simultaneously transferred by Agroinfection into N. benthamiana. A floral repressor GmRAV effector construct (35S:GmRAV-3F6H-pB7WG2) and proTPL:LUC were transferred into N. benthamiana as the negative control [43].

\subsection{Quantitative RT-PCR Analysis}

RNA isolation was performed as previously described [46]. QRT-PCR amplifications were performed using the TransStart ${ }^{\circledR}$ Tip Green qPCR SuperMix (TransGen Biotech, Beijing, China) on applied Biosystems ${ }^{\mathrm{TM}} 7500$ Fast Dx Real-Time PCR Instrument (Applied Biosystems, Foster City, CA, USA). The PCR cycling conditions: $94{ }^{\circ} \mathrm{C}$ for $30 \mathrm{~s} ; 40$ cycles of $94{ }^{\circ} \mathrm{C}$ for $5 \mathrm{~s} ; 50{ }^{\circ} \mathrm{C}$ for $34 \mathrm{~s}$. IPP2 (AT3G02780) and GmActin4 (GenBank accession number AF049106, National Center for Biotechnology Information, USA) were used as reference genes of Arabidopsis and soybean, respectively. The primers used in qRT-PCR analyses are shown in Table S2. Three biological replicates and three technical replicates were applied for all experiments.

\subsection{Statistical Analysis}

At least three biological replicates were included in the data, and all data were analyzed using Student's $t$-test or ANOVA, for the determination of the significant differences with SPSS 25.0 (IBM, Armonk, NY, USA). All data were analyzed using GraphPad Prism 8.0.2 (GraphPad Software, San Diego, CA, USA) for calculating mean and standard errors of the mean.

\section{Conclusions}

In conclusion, GmFULc binding with the promoter of target gene TPL and repressed the transcriptional of TPL, then weakened the inhibitory effect of TPL on FT and promoting the flowering. FT interacts with FD to activate downstream floral organ genes to induce flowering [47]. It is necessary to further investigate the molecular regulatory mechanism of GmFULc in soybean.

Supplementary Materials: The following are available online at https:/ /www.mdpi.com/article/10 .3390/ijms221910333/s1.

Author Contributions: J.S., Y.F. and Y.X. performed the gene cloning and ChIP assays. J.S., M.W. and C.Z. performed the phenotype observations and measurements. J.S., T.L. and Z.L. performed the dual-luciferase assay and data analysis. J.S., L.Z., X.Z. and W.L. wrote the manuscript. All authors have read and agreed to the published version of the manuscript.

Funding: This research was funded by the National Natural Science Foundation of China (32072086 and 31771820) and the Heilongjiang Province Natural Science Foundation (ZD2020C002).

Institutional Review Board Statement: Not applicable.

Informed Consent Statement: Not applicable.

Data Availability Statement: The ChIP-seq data names of the repositories and accession numbers can be found below: NCBI-SRA database under the BioProject no. PRJNA743583 and accession Nos. SRR15047998 and SRR15047997.

Conflicts of Interest: The authors declare no conflict of interest. 


\section{References}

1. Kantolic, A.G.; Slafer, G.A. Development and seed number in indeterminate soybean as affected by timing and duration of exposure to long photoperiods after flowering. Ann. Bot. 2007, 99, 925-933. [CrossRef]

2. Cober, E.R.; Morrison, M.J. Regulation of seed yield and agronomic characters by photoperiod sensitivity and growth habit genes in soybean. TAG Theor. Appl. Genet. Theor. Angew. Genet. 2010, 120, 1005-1012. [CrossRef]

3. Xu, M.; Xu, Z.; Liu, B.; Kong, F.; Tsubokura, Y.; Watanabe, S.; Xia, Z.; Harada, K.; Kanazawa, A.; Yamada, T.; et al. Genetic variation in four maturity genes affects photoperiod insensitivity and PHYA-regulated post-flowering responses of soybean. BMC Plant Biol. 2013, 13, 91. [CrossRef]

4. Wang, Y.; Gu, Y.; Gao, H.; Qiu, L.; Chang, R.; Chen, S.; He, C. Molecular and geographic evolutionary support for the essential role of GIGANTEAa in soybean domestication of flowering time. BMC Evol. Biol. 2016, 16, 79. [CrossRef]

5. Gramzow, T. A hitchhiker's guide to the MADS world of plants. Genome Biol. 2010, 11, AR 214. [CrossRef] [PubMed]

6. Zhang, Z.; Coenen, H.; Ruelens, P.; Hazarika, R.R.; Al Hindi, T.; Oguis, G.K.; Vandeperre, A.; van Noort, V.; Geuten, K. Resurrected Protein Interaction Networks Reveal the Innovation Potential of Ancient Whole-Genome Duplication. Plant Cell 2018, 30, 2741-2760. [CrossRef] [PubMed]

7. Zhang, Y.; Tang, D.; Lin, X.; Ding, M.; Tong, Z. Genome-wide identification of MADS-box family genes in moso bamboo (Phyllostachys edulis) and a functional analysis of PeMADS5 in flowering. BMC Plant Biol. 2018, 18, 176. [CrossRef]

8. Mandel, M.A. The Arabidopsis AGL8 MADS Box Gene Is Expressed in Inflorescence Meristems and Is Negatively Regulated by APETALA1. Plant Cell Online 1995, 7, 1763-1771. [CrossRef]

9. Litt, A.; Irish, V.F. Duplication and diversification in the APETALA1/FRUITFULL floral homeotic gene lineage: Implications for the evolution of floral development. Genetics 2003, 165, 821-833. [CrossRef] [PubMed]

10. Ferrándiz, C.; Gu, Q.; Martienssen, R.; Yanofsky, M.F. Redundant regulation of meristem identity and plant architecture by FRUITFULL, APETALA1 and CAULIFLOWER. Development 2000, 127, 725-734. [CrossRef]

11. Melzer, S.; Lens, F.; Gennen, J.; Vanneste, S.; Rohde, A.; Beeckman, T. Flowering-time genes modulate meristem determinacy and growth form in Arabidopsis thaliana. Nat. Genet. 2008, 40, 1489-1492. [CrossRef]

12. Torti, S.; Fornara, F.; Vincent, C.; Andres, F.; Nordstrom, K.; Gobel, U.; Knoll, D.; Schoof, H.; Coupland, G. Analysis of the Arabidopsis shoot meristem transcriptome during floral transition identifies distinct regulatory patterns and a leucine-rich repeat protein that promotes flowering. Plant Cell 2012, 24, 444-462. [CrossRef]

13. Corbesier, L.; Vincent, C.; Jang, S.; Fornara, F.; Fan, Q.; Searle, I.; Giakountis, A.; Farrona, S.; Gissot, L.; Turnbull, C.; et al. FT protein movement contributes to long-distance signaling in floral induction of Arabidopsis. Science 2007, 316, 1030-1033. [CrossRef]

14. de Folter, S.; Immink, R.G.; Kieffer, M.; Parenicova, L.; Henz, S.R.; Weigel, D.; Busscher, M.; Kooiker, M.; Colombo, L.; Kater, M.M.; et al. Comprehensive interaction map of the Arabidopsis MADS Box transcription factors. Plant Cell 2005, 17, 1424-1433. [CrossRef]

15. Balanza, V.; Martinez-Fernandez, I.; Ferrandiz, C. Sequential action of FRUITFULL as a modulator of the activity of the floral regulators SVP and SOC1. J. Exp. Bot. 2014, 65, 1193-1203. [CrossRef]

16. de Folter, S.; Angenent, G.C. trans meets cis in MADS science. Trends Plant Sci. 2006, 11, 224-231. [CrossRef]

17. Kobayashi, K.; Yasuno, N.; Sato, Y.; Yoda, M.; Yamazaki, R.; Kimizu, M.; Yoshida, H.; Nagamura, Y.; Kyozuka, J. Inflorescence meristem identity in rice is specified by overlapping functions of three AP1/FUL-like MADS box genes and PAP2, a SEPALLATA MADS box gene. Plant Cell 2012, 24, 1848-1859. [CrossRef] [PubMed]

18. Bemer, M.; Karlova, R.; Ballester, A.R.; Tikunov, Y.M.; Bovy, A.G.; Wolters-Arts, M.; Rossetto Pde, B.; Angenent, G.C.; de Maagd, R.A. The tomato FRUITFULL homologs TDR4/FUL1 and MBP7/FUL2 regulate ethylene-independent aspects of fruit ripening. Plant Cell 2012, 24, 4437-4451. [CrossRef] [PubMed]

19. Fujisawa, M.; Shima, Y.; Nakagawa, H.; Kitagawa, M.; Kimbara, J.; Nakano, T.; Kasumi, T.; Ito, Y. Transcriptional regulation of fruit ripening by tomato FRUITFULL homologs and associated MADS box proteins. Plant Cell 2014, 26, 89-101. [CrossRef]

20. Shima, Y.; Fujisawa, M.; Kitagawa, M.; Nakano, T.; Kimbara, J.; Nakamura, N.; Shiina, T.; Sugiyama, J.; Nakamura, T.; Kasumi, T.; et al. Tomato FRUITFULL homologs regulate fruit ripening via ethylene biosynthesis. Biosci. Biotechnol. Biochem. 2014, 78, 231-237. [CrossRef] [PubMed]

21. Zhao, J.; Jiang, L.; Che, G.; Pan, Y.; Li, Y.; Hou, Y.; Zhao, W.; Zhong, Y.; Ding, L.; Yan, S.; et al. A functional allele of CsFUL1 regulates fruit length through inhibiting CsSUP and auxin transport in cucumber. Plant Cell 2019. [CrossRef]

22. Chi, Y.; Wang, T.; Xu, G.; Yang, H.; Zeng, X.; Shen, Y.; Yu, D.; Huang, F. GmAGL1, a MADS-Box Gene from Soybean, Is Involved in Floral Organ Identity and Fruit Dehiscence. Front. Plant Sci. 2017, 8, 175. [CrossRef]

23. Zeng, X.; Liu, H.; Du, H.; Wang, S.; Yang, W.; Chi, Y.; Wang, J.; Huang, F.; Yu, D. Soybean MADS-box gene GmAGL1 promotes flowering via the photoperiod pathway. BMC Genom. 2018, 19, 51. [CrossRef]

24. Lyu, J.; Cai, Z.; Li, Y.; Suo, H.; Yi, R.; Zhang, S.; Nian, H. The Floral Repressor GmFLC-like Is Involved in Regulating Flowering Time Mediated by Low Temperature in Soybean. Int. J. Mol. Sci. 2020, 21, 1322. [CrossRef] [PubMed]

25. Zhao, L.; Li, M.; Xu, C.; Yang, X.; Li, D.; Zhao, X.; Wang, K.; Li, Y.; Zhang, X.; Liu, L.; et al. Natural variation in GmGBP1 promoter affects photoperiod control of flowering time and maturity in soybean. Plant J. Cell Mol. Biol. 2018, 96, 147-162. [CrossRef]

26. Yang, X.; Li, X.; Shan, J.; Li, Y.; Zhang, Y.; Wang, Y.; Li, W.; Zhao, L. Overexpression of GmGAMYB Accelerates the Transition to Flowering and Increases Plant Height in Soybean. Front. Plant Sci. 2021, 12. [CrossRef] [PubMed] 
27. Liu, Z.; Karmarkar, V. Groucho/Tup1 family co-repressors in plant development. Trends Plant Sci. 2008, 13, 137-144. [CrossRef] [PubMed]

28. Wang, L.; Kim, J.; Somers, D.E. Transcriptional corepressor TOPLESS complexes with pseudoresponse regulator proteins and histone deacetylases to regulate circadian transcription. Proc. Natl. Acad. Sci. USA 2013, 110, 761-766. [CrossRef] [PubMed]

29. Causier, B.; Ashworth, M.; Guo, W.; Davies, B. The TOPLESS interactome: A framework for gene repression in Arabidopsis. Plant Physiol. 2012, 158, 423-438. [CrossRef] [PubMed]

30. Goralogia, G.S.; Liu, T.K.; Zhao, L.; Panipinto, P.M.; Groover, E.D.; Bains, Y.S.; Imaizumi, T. CYCLING DOF FACTOR 1 represses transcription through the TOPLESS co-repressor to control photoperiodic flowering in Arabidopsis. Plant J. Cell Mol. Biol. 2017, 92, 244-262. [CrossRef]

31. Heinz, S.; Benner, C.; Spann, N.; Bertolino, E.; Lin, Y.C.; Laslo, P.; Cheng, J.X.; Murre, C.; Singh, H.; Glass, C.K. Simple combinations of lineage-determining transcription factors prime cis-regulatory elements required for macrophage and B cell identities. Mol. Cell 2010, 38, 576-589. [CrossRef] [PubMed]

32. Bemer, M.; van Mourik, H.; Muino, J.M.; Ferrandiz, C.; Kaufmann, K.; Angenent, G.C. FRUITFULL controls SAUR10 expression and regulates Arabidopsis growth and architecture. J. Exp. Bot. 2017, 68, 3391-3403. [CrossRef] [PubMed]

33. Zhao, L.; Luo, Q.; Yang, C.; Han, Y.; Li, W. A RAV-like transcription factor controls photosynthesis and senescence in soybean. Planta 2008, 227, 1389-1399. [CrossRef] [PubMed]

34. Ferrario, S.; Busscher, J.; Franken, J.; Gerats, T.; Vandenbussche, M.; Angenent, G.C.; Immink, R.G. Ectopic expression of the petunia MADS box gene UNSHAVEN accelerates flowering and confers leaf-like characteristics to floral organs in a dominantnegative manner. Plant Cell 2004, 16, 1490-1505. [CrossRef]

35. Yu, X.; Duan, X.; Zhang, R.; Fu, X.; Ye, L.; Kong, H.; Xu, G.; Shan, H. Prevalent Exon-Intron Structural Changes in the APETALA1/FRUITFULL, SEPALLATA, AGAMOUS-LIKE6, and FLOWERING LOCUS C MADS-Box Gene Subfamilies Provide New Insights into Their Evolution. Front. Plant Sci. 2016, 7, 598. [CrossRef]

36. Jia, Z.; Jiang, B.; Gao, X.; Yue, Y.; Fei, Z.; Sun, H.; Wu, C.; Sun, S.; Hou, W.; Han, T. GmFULa, a FRUITFULL homolog, functions in the flowering and maturation of soybean. Plant Cell Rep. 2015, 34, 121-132. [CrossRef]

37. Teper-Bamnolker, P.; Samach, A. The flowering integrator FT regulates SEPALLATA3 and FRUITFULL accumulation in Arabidopsis leaves. Plant Cell 2005, 17, 2661-2675. [CrossRef]

38. Liu, W.; Jiang, B.; Ma, L.; Zhang, S.; Zhai, H.; Xu, X.; Hou, W.; Xia, Z.; Wu, C.; Sun, S.; et al. Functional diversification of Flowering Locus T homologs in soybean: GmFT1a and GmFT2a/5a have opposite roles in controlling flowering and maturation. New Phytol. 2018, 217, 1335-1345. [CrossRef]

39. Tao, Q.; Guo, D.; Wei, B.; Zhang, F.; Pang, C.; Jiang, H.; Zhang, J.; Wei, T.; Gu, H.; Qu, L.J.; et al. The TIE1 transcriptional repressor links TCP transcription factors with TOPLESS/TOPLESS-RELATED corepressors and modulates leaf development in Arabidopsis. Plant Cell 2013, 25, 421-437. [CrossRef]

40. Zheng, T.; Tan, W.; Yang, H.; Zhang, L.; Li, T.; Liu, B.; Zhang, D.; Lin, H. Regulation of anthocyanin accumulation via MYB75/HAT1/TPL-mediated transcriptional repression. PLoS Genet. 2019, 15, e1007993. [CrossRef] [PubMed]

41. Szemenyei, H.; Hannon, M.; Long, J.A. TOPLESS mediates auxin-dependent transcriptional repression during Arabidopsis embryogenesis. Science 2008, 319, 1384-1386. [CrossRef]

42. Pauwels, L.; Barbero, G.F.; Geerinck, J.; Tilleman, S.; Grunewald, W.; Perez, A.C.; Chico, J.M.; Bossche, R.V.; Sewell, J.; Gil, E.; et al. NINJA connects the co-repressor TOPLESS to jasmonate signalling. Nature 2010, 464, 788-791. [CrossRef] [PubMed]

43. Yang, X.; Zhang, Y.; Shan, J.; Sun, J.; Li, D.; Zhang, X.; Li, W.; Zhao, L. GmIDD Is Induced by Short Days in Soybean and May Accelerate Flowering When Overexpressed in Arabidopsis via Inhibiting AGAMOUS-LIKE 18. Front. Plant Sci. 2021, 12, 629069. [CrossRef] [PubMed]

44. Clough, S.; Bent, A. Floral dip: A simplified method for Agrobacterium-mediated transformation of Arabidopsis thaliana. Plant J. Cell Mol. Biol. 1998, 16, 735-743. [CrossRef] [PubMed]

45. Yamaguchi, N.; Winter, C.M.; Wu, M.F.; Kwon, C.S.; William, D.A.; Wagner, D. PROTOCOLS: Chromatin Immunoprecipitation from Arabidopsis Tissues. Arab. Book 2014, 12, e0170. [CrossRef]

46. Zhao, L.; Wang, Z.; Lu, Q.; Wang, P.; Li, Y.; Lv, Q.; Song, X.; Li, D.; Gu, Y.; Liu, L.; et al. Overexpression of a GmGBP1 ortholog of soybean enhances the responses to flowering, stem elongation and heat tolerance in transgenic tobaccos. Plant Mol. Biol. 2013, 82, 279-299. [CrossRef]

47. Abe, M.; Kobayashi, Y.; Yamamoto, S.; Daimon, Y.; Yamaguchi, A.; Ikeda, Y.; Ichinoki, H.; Notaguchi, M.; Goto, K.; Araki, T. FD, a bZIP Protein Mediating Signals from the Floral Pathway Integrator FT at the Shoot Apex. Science 2005, 309, 1052-1056. [CrossRef] 